\title{
WIND ANALYSIS OF SQUARE AND RECTANGULAR GEOMETRY MULTISTORIED BUILDING
}

\author{
Bhumika Pashine $^{1}$, V. D. Vaidya ${ }^{2}$, Valsson Varghese ${ }^{3}$, D. P. Singh ${ }^{4}$ \\ ${ }^{I}$ Student, M Tech, Structural Engineering, KDK College of Engineering., Maharashtra, India \\ ${ }^{2}$ Assistant Professor, Civil Engineering Department, KDK College of Engineering., Maharashtra, India \\ ${ }^{3}$ Professor and Head of Civil Engineering Department, KDK College of Engineering., Maharashtra, India \\ ${ }^{4}$ Principal and Professor, Civil Engineering Department, KDK College of Engineering., Maharashtra, India
}

\begin{abstract}
Its today's trend that we are expanding vertically instead of horizontally and constructing tall structures, either due unavailability of land or due man's desire to achieve something which unachievable and challenge himself. However whatever be the case as when we increase the height of the structure wind load becomes one of the most predominating factor in the design of any high rise structure, hence it is very important that a structural engineer should understand how the structure will behave as the height increases.In this paper effect of wind on tall structure is studied and analyzed, two geometry, square and rectangular with same plan area were selected. Software models for these two geometries were made in STAAD with three different storeyheightsi.e 15 storey, 25 storey and 30 storey and models were analyzed for both along and across wind condition for various parametric values.
\end{abstract}

Keywords: Wind analysis, Tall Structure, Square shape geometry, Rectangular shape geometry, Variation in height

\section{INTRODUCTION}

Now a days it has become necessity to construct tall building for offices as well as residential purpose in big cities, to accommodate ever increasing population growth in available amount of space,especially in developing country like India. These building are generally designed for square and rectangular shape cross section.As the height of structures increases it becomes more complex, it is vital that the structural engineers must know theperformanceof the buildingagainst wind pressure in order to create costeffective designs satisfying serviceability requirements, as wind pressure is one of the dominating factors during design of tall buildings. For design of building considering the effect of wind loads, design engineers use values of wind pressure coefficient given in relevant handbooks or standards for wind loads, in India IS: 875 (Part-3) 1987) is used.

J. A. Amin and A. K. Ahuja (2008) has done experimental study of wind pressures on irregular plan shape buildings[1], and concluded that changing the plan dimension has subsequent effect on the wind pressure and thus on behavior of structure.Yi Tang and Xin-yang Jin (2009) has done study on equivalent Static Wind Loads of an Asymmetric Building with 3D Coupled Modes[2], and concluded that peak responses obtained by applying Equivalent static wind loading are very close with results calculated by CQC (Complete Quadratic Combination) methods.C.M. Chana, M.F. Huangb, K.C.S. Kwokc (2010) [3], has done Integrated wind load analysis and stiffness optimization of tall buildings with 3D modes and discovered that by stiffness optimization methodwind-induced torsional loads on the building with the irregular plan have been significantly reduced.Yi Hui n, Yukio Tamura, Akihito Yoshida (2012) [4], has studied the effect of mutaul interference between two tall building models with different geometry on local peak pressure coefficients and found thatthe effect of peak coefficient greatly depend on building shapes and wind directions.Rachel Bashor,Sarah Bobby , Tracy Kijewski-Correa, Ahsan Kareem (2012) [5] studied full-scale performance evaluation of high rise buildings under wind pressure.Michael Jesson, Mark Sterling, Chris Letchford, Chris Baker, (2015),[6] studied about aerodynamic forces due to transient windson the roofs of low-, mid- and high-rise buildings and concluded that pressure coefficients are of greatest magnitude when the roof is above the region of maximum outflow velocity.

\section{PROBLEM STATEMENT}

This paper is an attempt to study behavior of the tall buildings under wind load and to evaluate analytical techniques to compute dynamic response and present a detailed comparison for two different plan geometry with three storey heights i.e. 15, 25, 30 storeyalong and across wind direction.

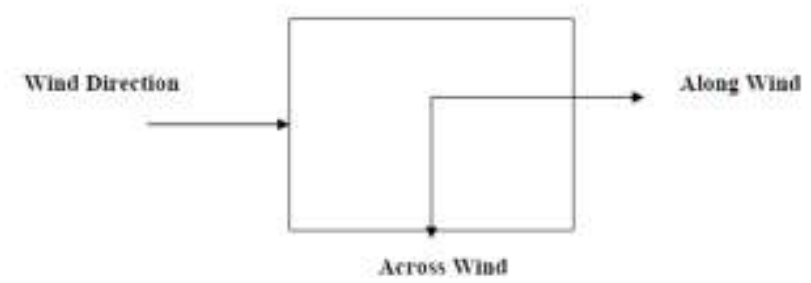

Fig -1: Along and Across Wind Response 


\subsection{Geometry of building:}

$>$ Type of building

$>$ Plinth area

: Commercial

$>$ Floor Height : $3.5 \mathrm{~m}$

$>$ Depth of foundation $: 2.0 \mathrm{~m}$
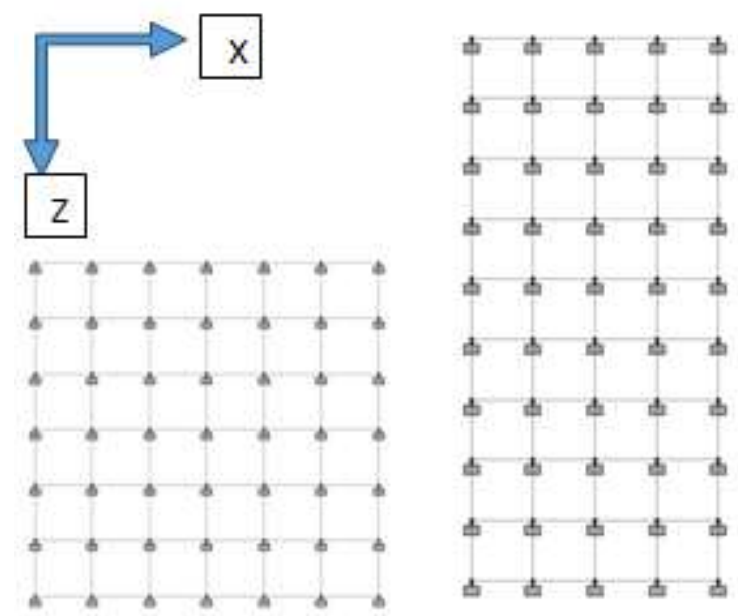

Fig -2: Square plan (Model-M1) aspect ratio 1 and rectangular plan (Model-M2) aspect ratio 2.25

\subsection{Wind Data}

$>$ As per IS 875-Part III

$>$ Basic Wind Speed of Nagpur: $44 \mathrm{~m} / \mathrm{s}$

$>$ Terrain Category: III

\subsection{Software Modeling}

Computer modeling of the building is performed using the finite element software STAAD-Pro. R.C Buildings of different storey are modeled as beam-column building composed of columns, beams as shown in Figure $3 \& 4$. The columns are assumed to be fixed at their base. A detailed three-dimensional model is employed for wind analysis.

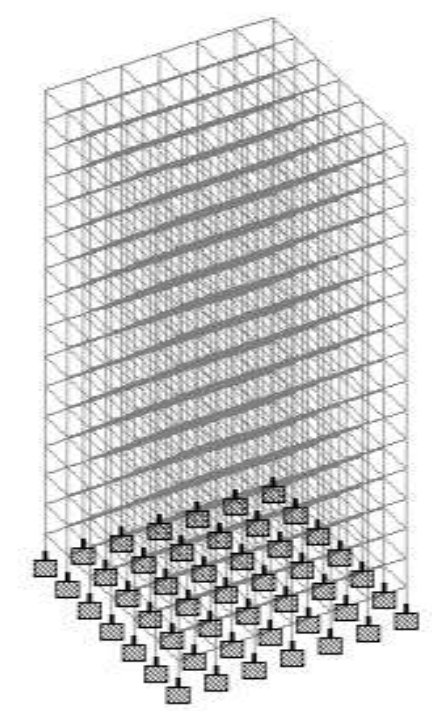

Fig -3: Typical3-D model for Square geometry (Model-M1)

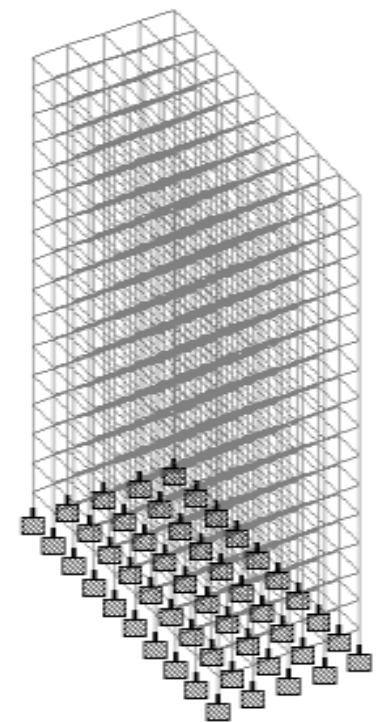

Fig -4:Typical3-D model for Rectangular geometry (ModelM1)

\section{RESULTS AND DISCUSSION}

Variation in various parameter such as maximum displacement, storey drift, axial force, shear force, bending moment and torsional moment is worked out after performing analysis. The results are compared in two categories, (i) variation in parametric values due to change in geometry (from chart 1 to 18), (ii) variation in parametric values per unit length due to change in height (from chart 19 to 27 ).

\subsection{Variation in Parametric Values Due To Change in Geometry}

\subsubsection{For 15 Storey Structure}

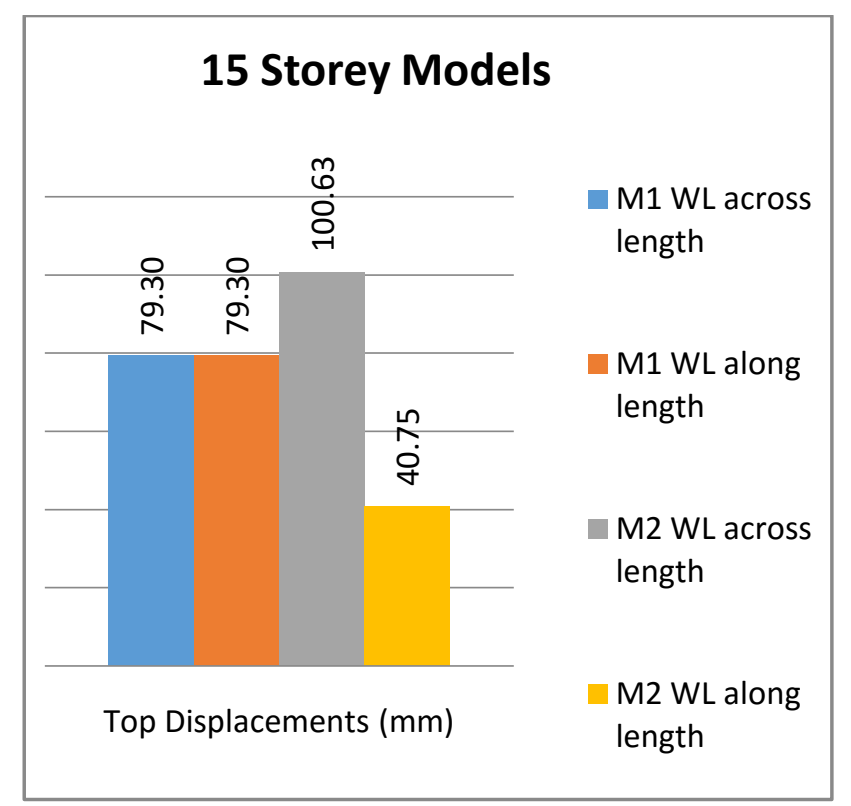

Chart -1: Variation of maximum displacement in model M1 and M2, 15 storey for wind load along and across length 


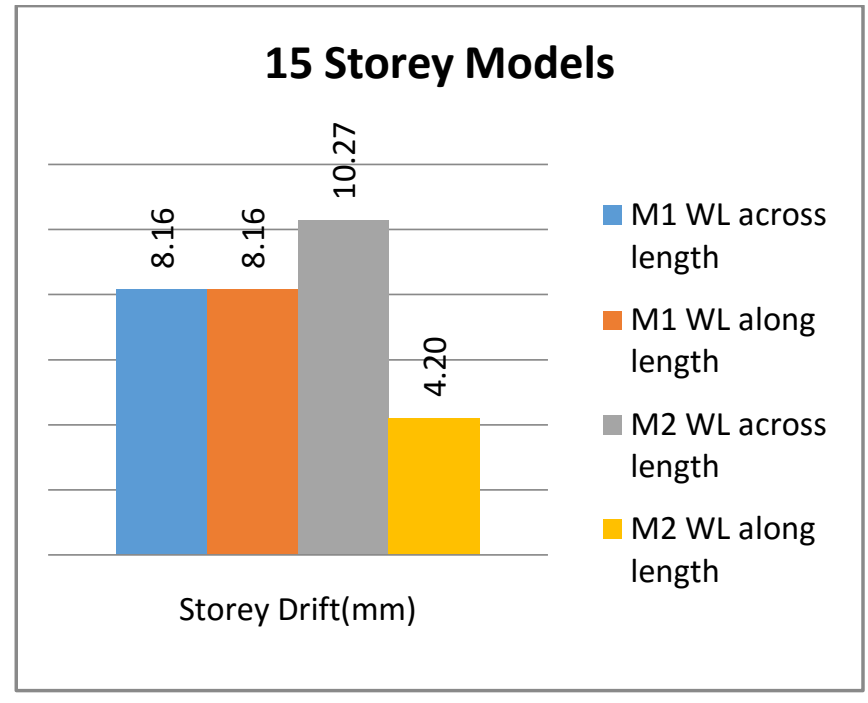

Chart -2: Variation of Storey drift in model M1 and M2, 15 storey for wind load along and across length

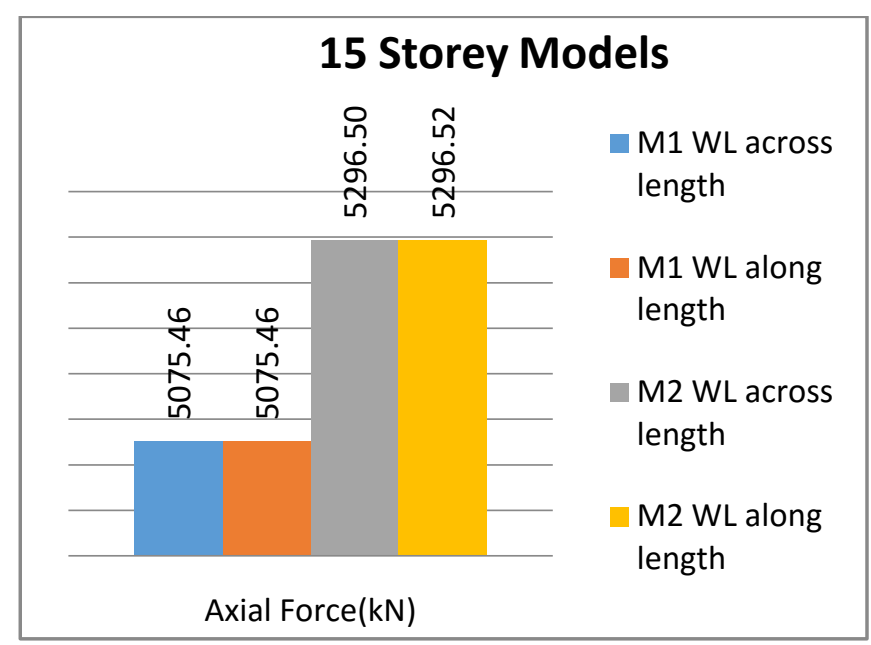

Chart -3: Variation of Axial Force in model M1 and M2, 15 storey for wind load along and across length

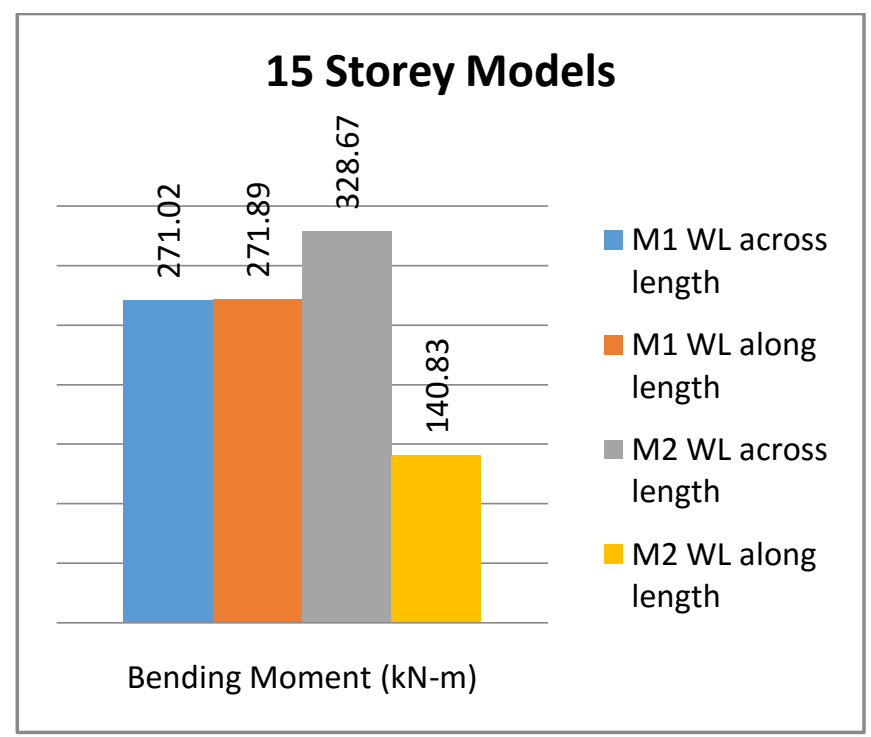

Chart -4: Variation of Bending Moment in model M1 and M2, 15 storey for wind load along and across length

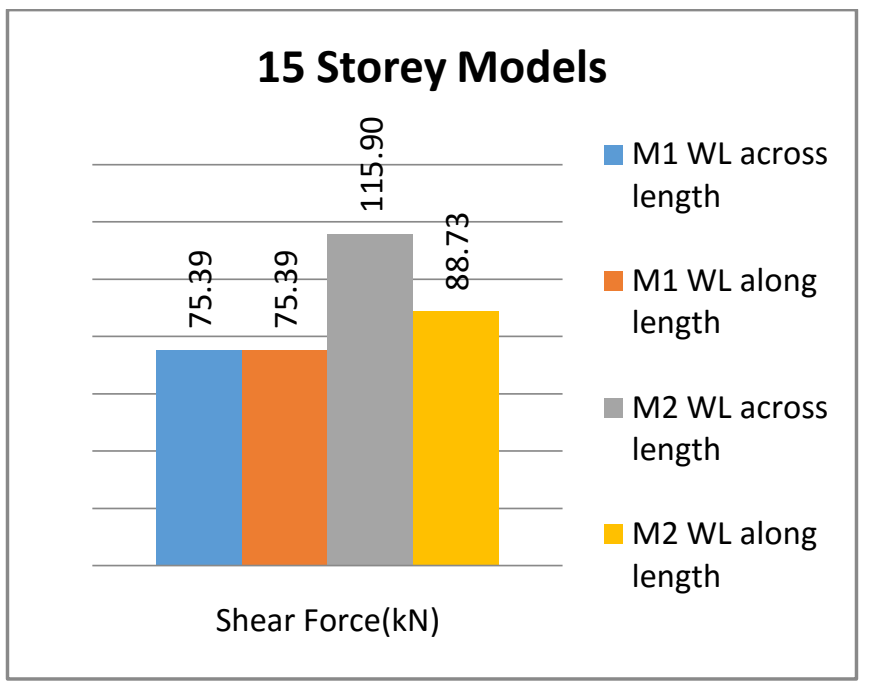

Chart -5: Variation of Shear Force in model M1 and M2, 15 storey for wind load along and across length

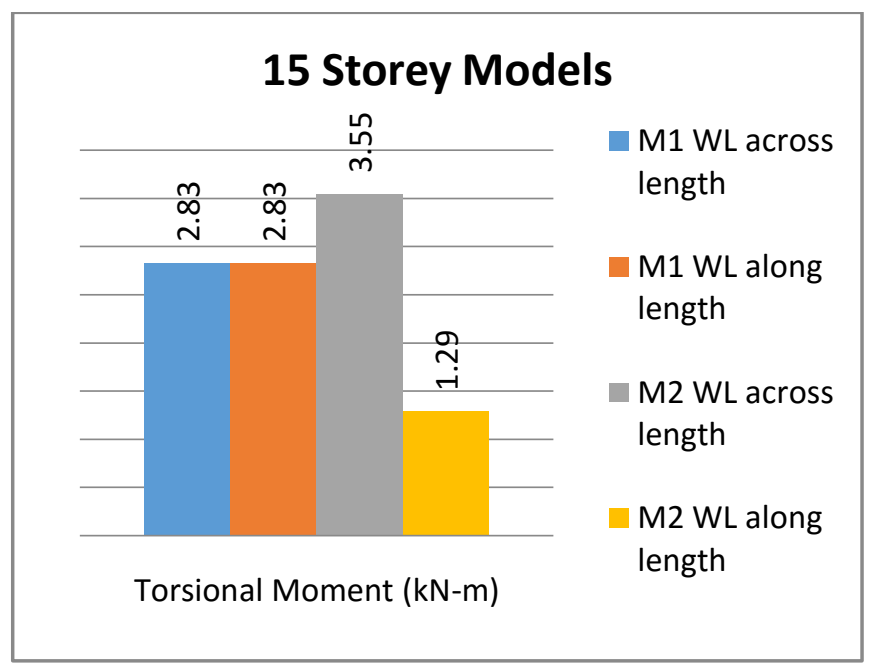

Chart -6: Variation of Torsional Moment in model M1 and M2, 15 storey for wind load along and across length

\subsubsection{For25 Storey Structure}

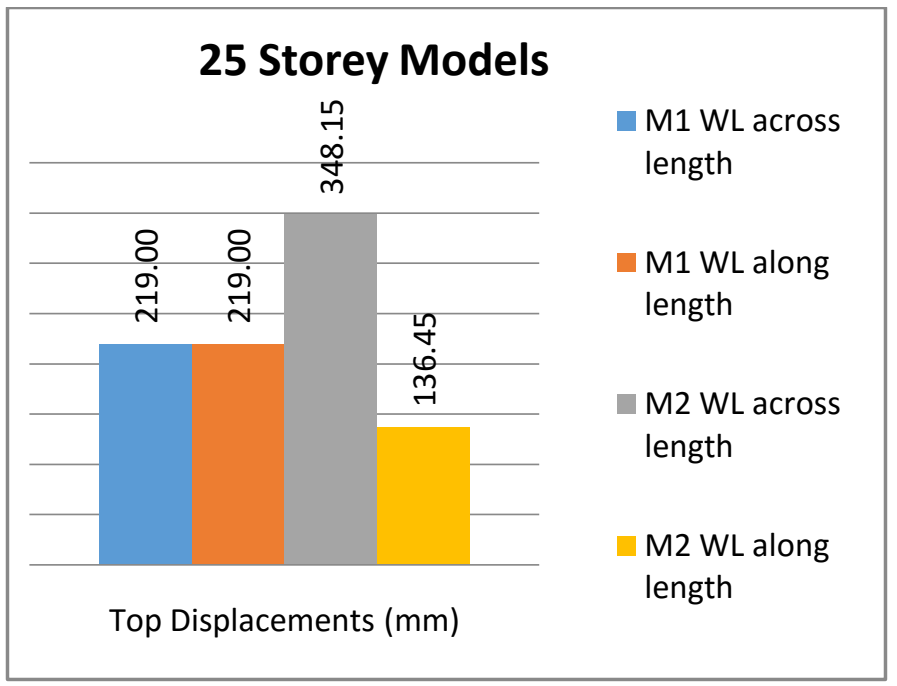

Chart -7: Variation of maximum displacement in model M1 and M2, 25 storey for wind load along and across length 


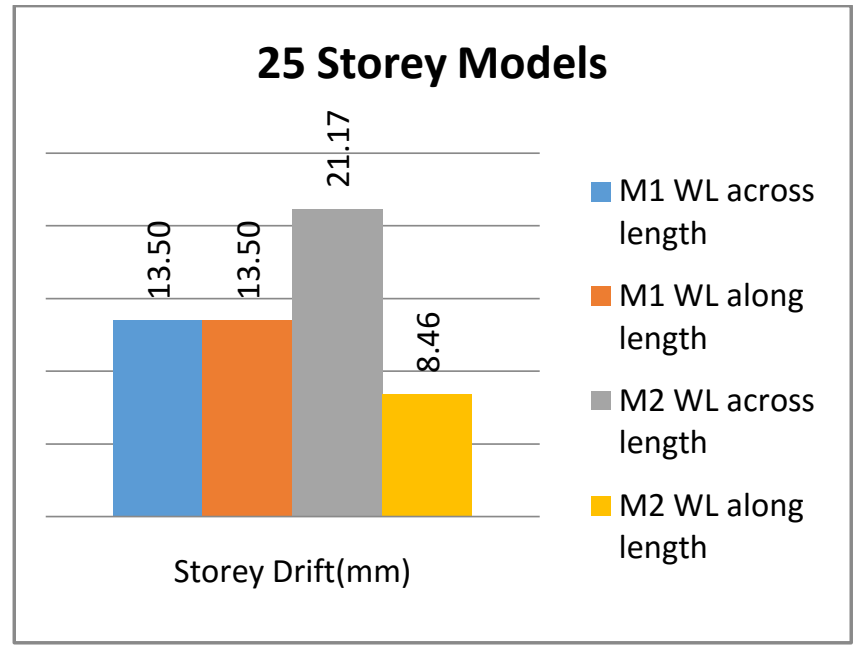

Chart -8: Variation of Storey Drift in model M1 and M2, 25 storey for wind load along and across length

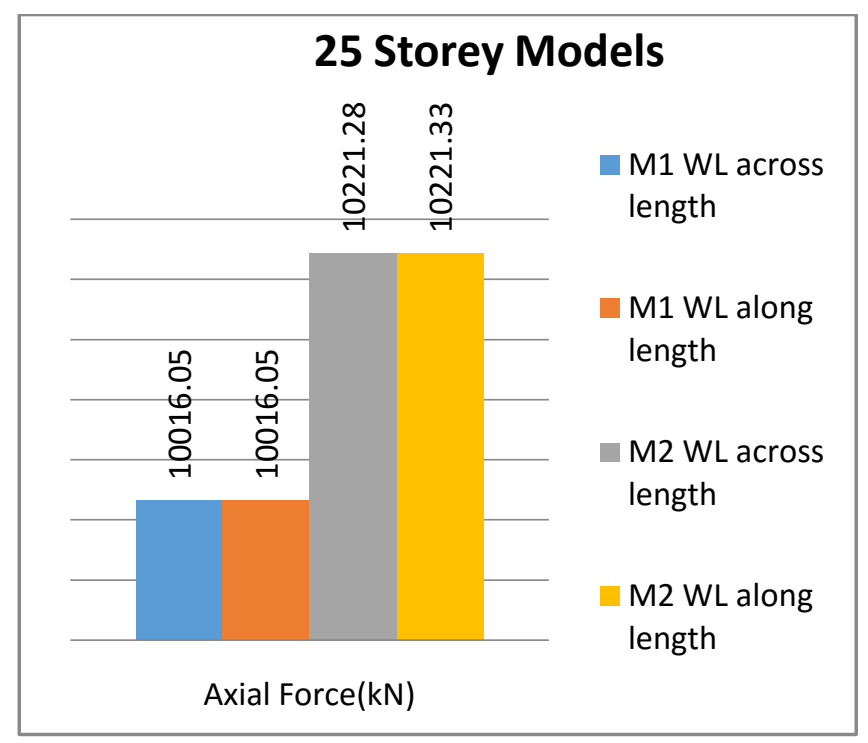

Chart -9: Variation of Axial Force in model M1 and M2, 25 storey for wind load along and across length

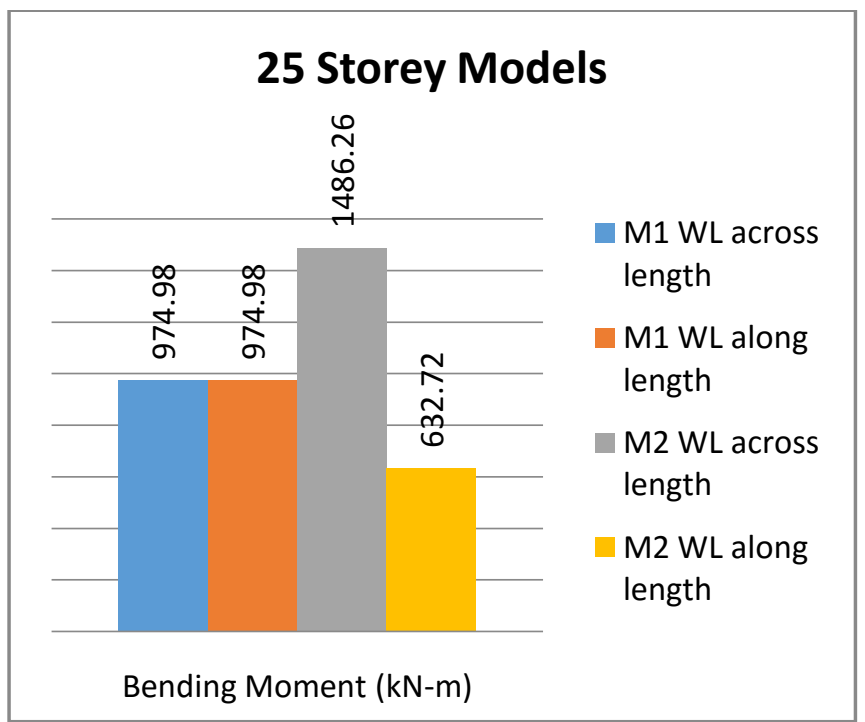

Chart -10: Variation of Bending Moment in model M1 and M2, 25 storey for wind load along and across length

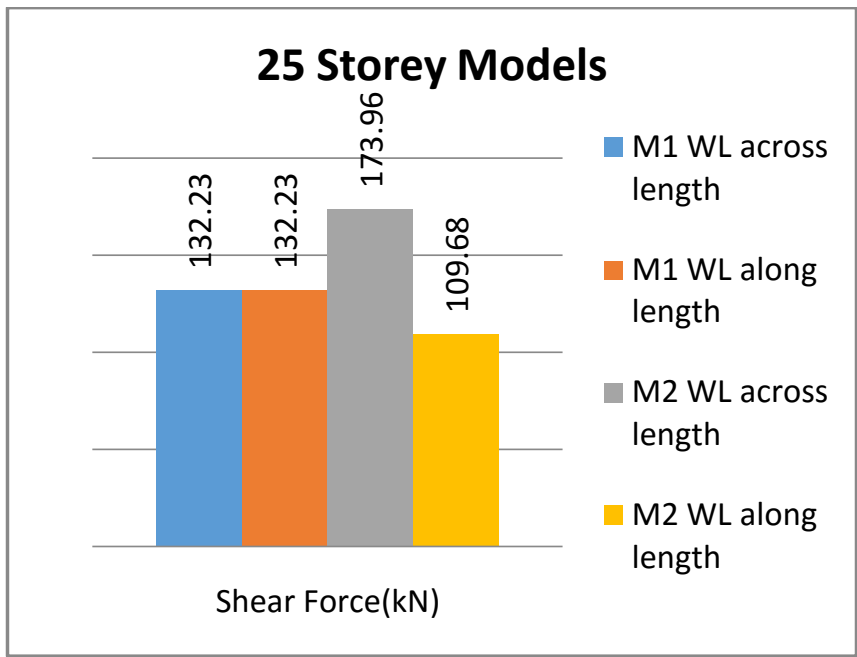

Chart -11: Variation of Shear Force in model M1 and M2, 25 storey for wind load along and across length

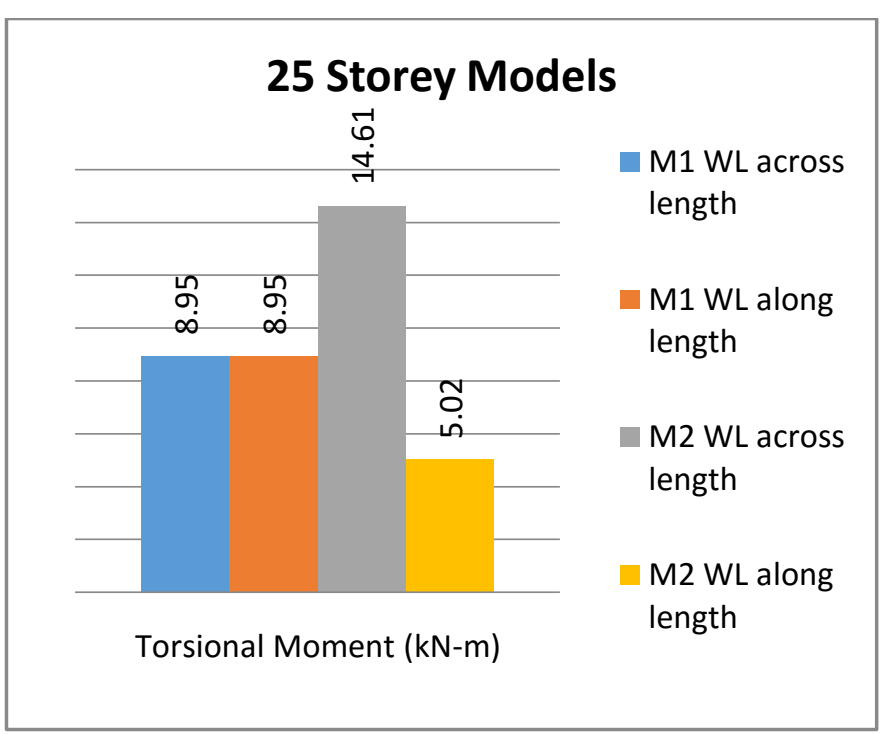

Chart -12: Variation of Torsional Moment in model M1 and M2, 25 storey for wind load along and across length

\subsubsection{For30Storey Structure}

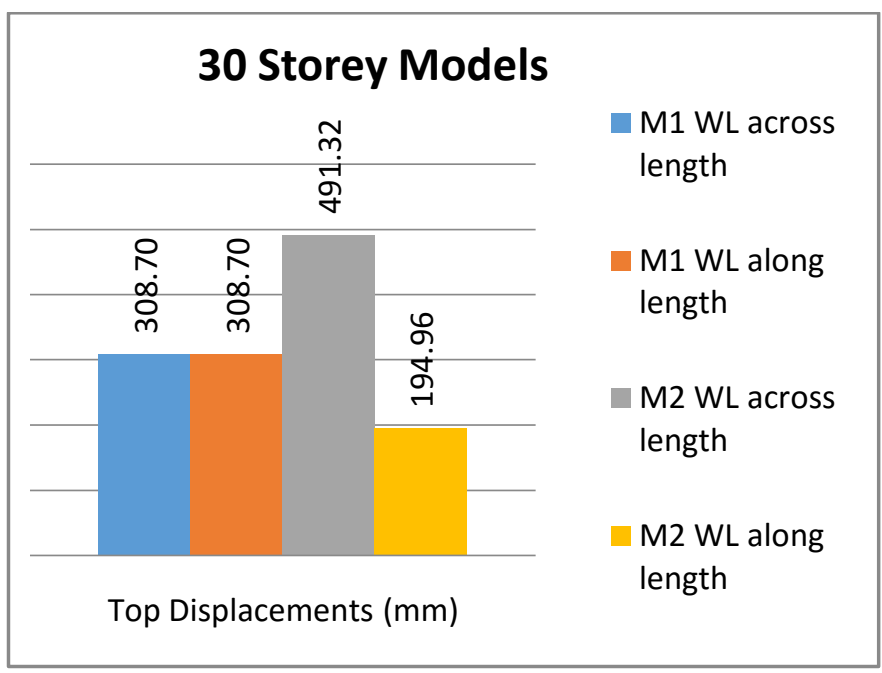

Chart -13: Variation of maximum displacement in model M1 and M2, 30 storey for wind load along and across length 


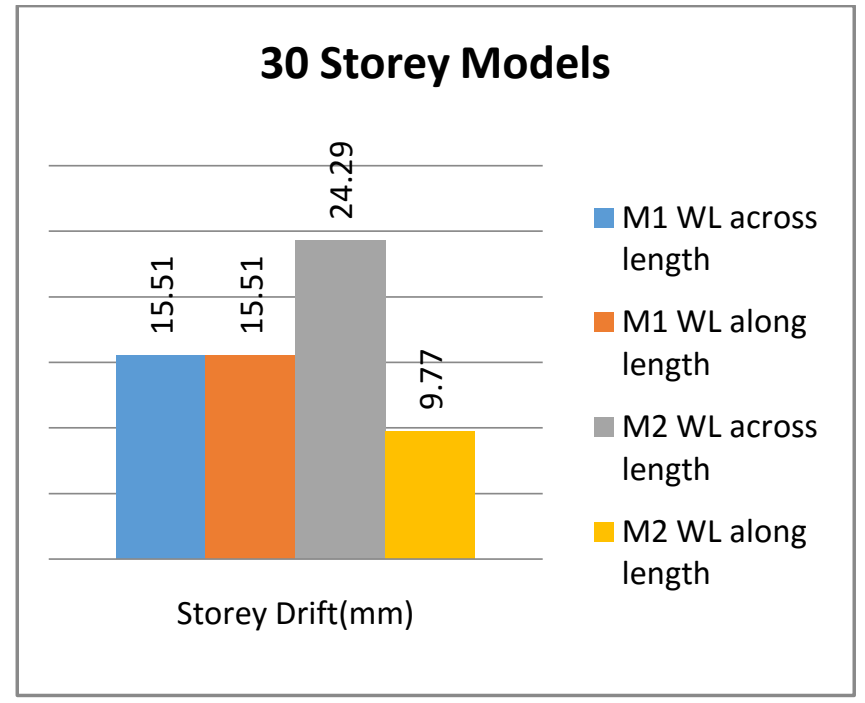

Chart -14: Variation of Storey Drift in model M1 and M2, 30 storey for wind load along and across length

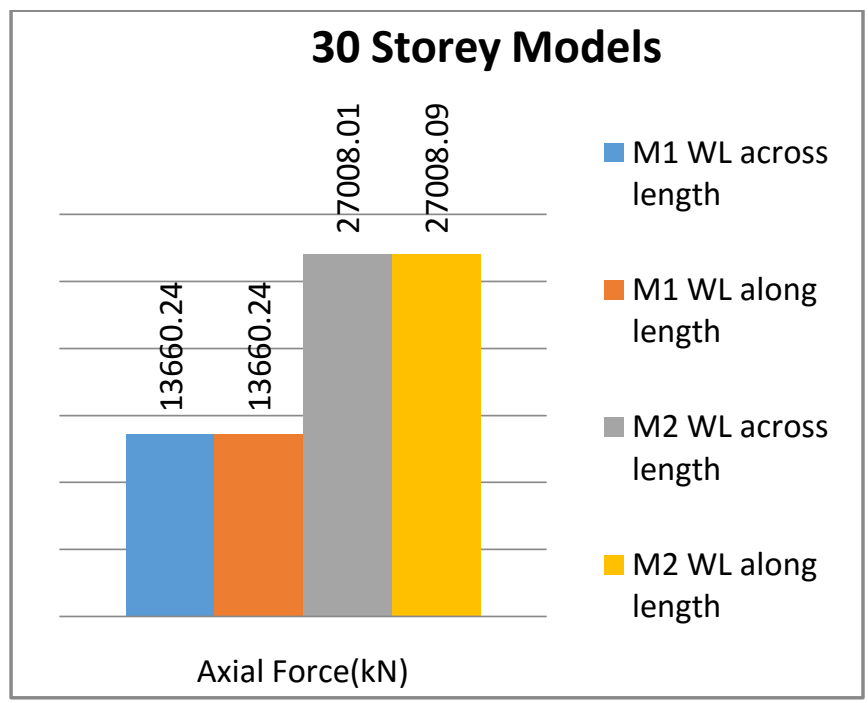

Chart -15: Variation of Axial force in model M1 and M2, 30 storey for wind load along and across length

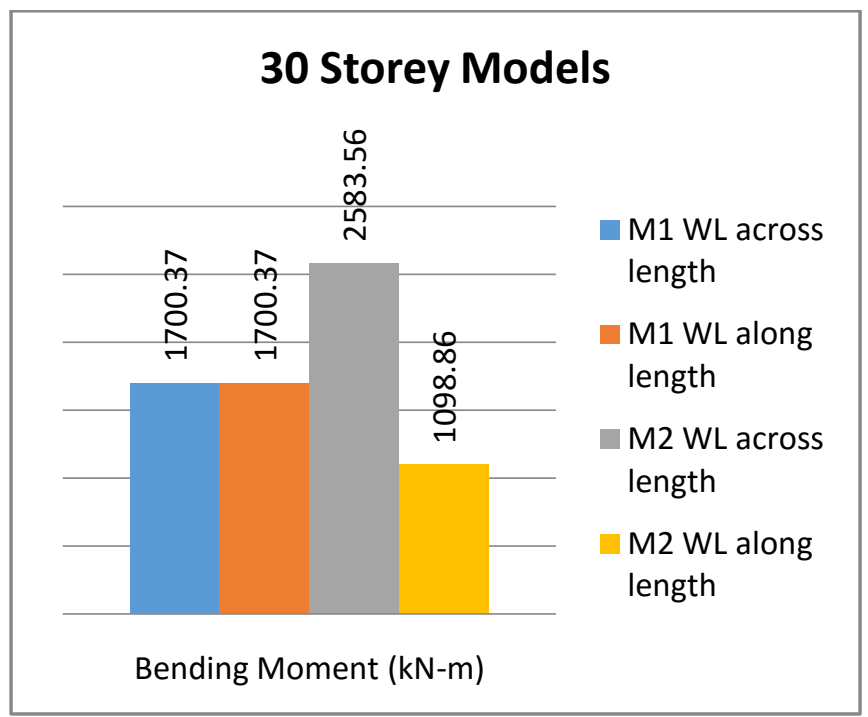

Chart -16: Variation of Bending moment in model M1 and M2, 30 storey for wind load along and across length

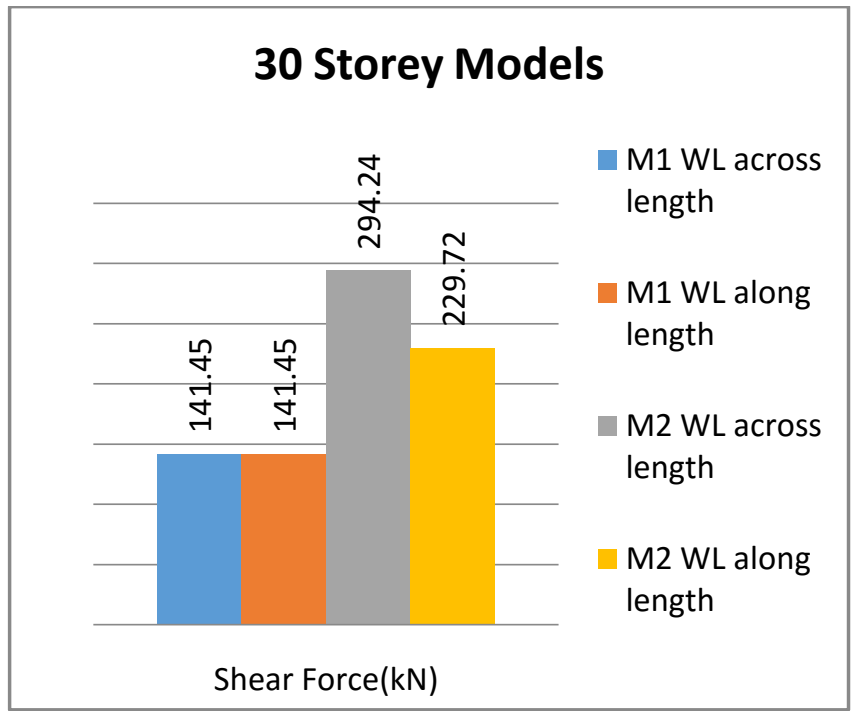

Chart -17: Variation of Shear force in model M1 and M2, 30 storey for wind load along and across length

\section{Storey Models}

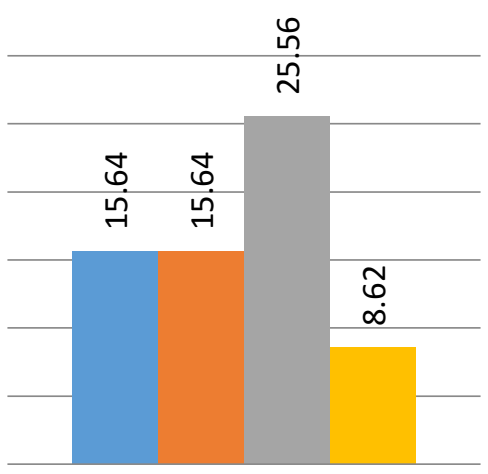

- M1 WL across length

M1 WL along length

M2 WL across length

M2 WL along length

Torsional Moment (kN-m)

Chart -18: Variation of Torsional moment in model M1 and M2, 30 storey for wind load along and across length

From chart 1 to 18 , it can be seen that in case of square geometry direction of wind does not affect the behavior of structure at any height as stiffness is same in both direction whereas in case of rectangular geometry parametric values are considerably more if wind pressure is acting across the length of the structure then wind direction along the length as stiffness of building is more when wind acts along the length.

\subsection{Variation In Parametric Values Per Unit Length Due To Change In Height}

In this case comparative study is done in the form of chart for same geometry but different building height for various parametric characteristics. 
3.2.1 ForSquare Geometry

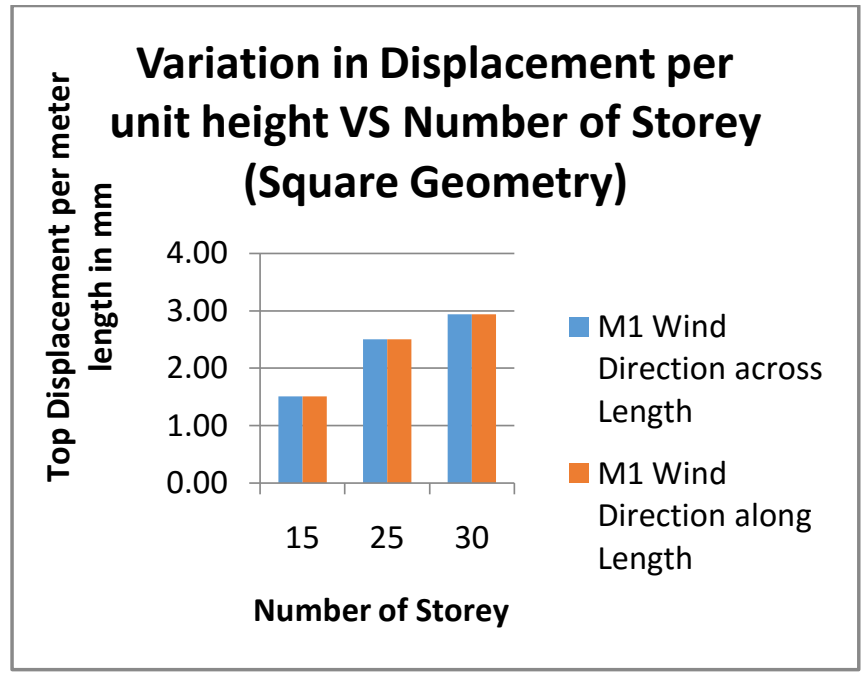

Chart -19: Variation in Displacement per unit height in model M1 VS No. of storey

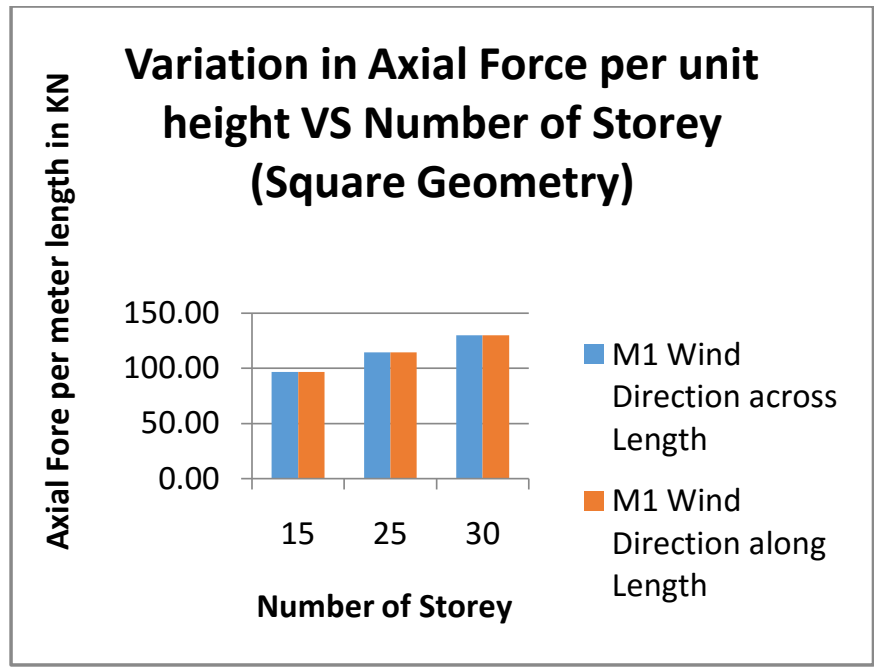

Chart -20: Variation in Axial Force per unit height in model M1 VS No. of storey

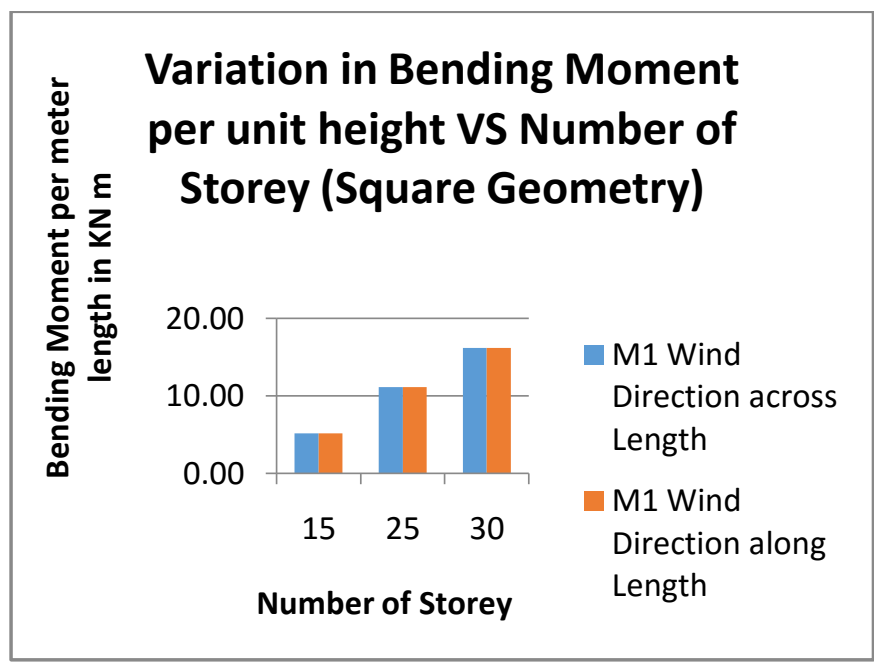

Chart -21: Variation in Bending Moment per unit height in model M1 VS No. of storey

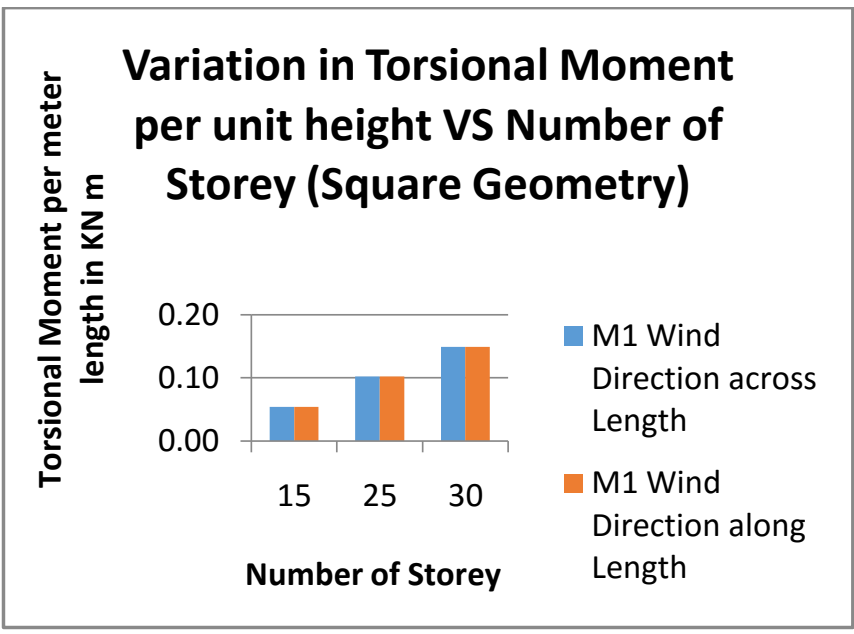

Chart -22: Variation in Torsional Moment per unit height in model M1 VS No. of storey

\subsubsection{ForRectangular Geometry}

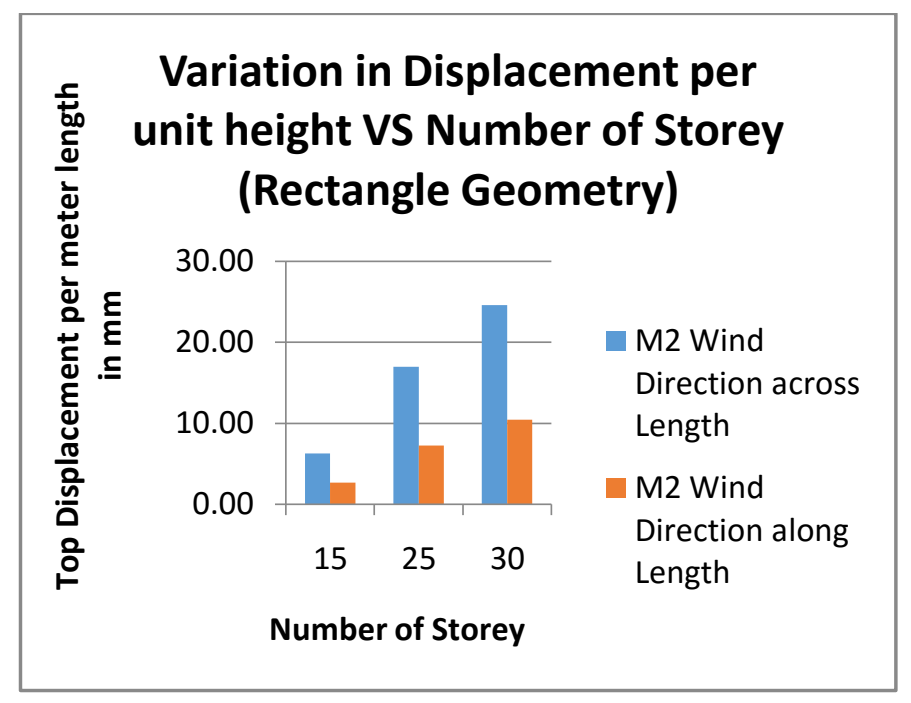

Chart -23: Variation in Displacement per unit height in model M2 VS No. of storey

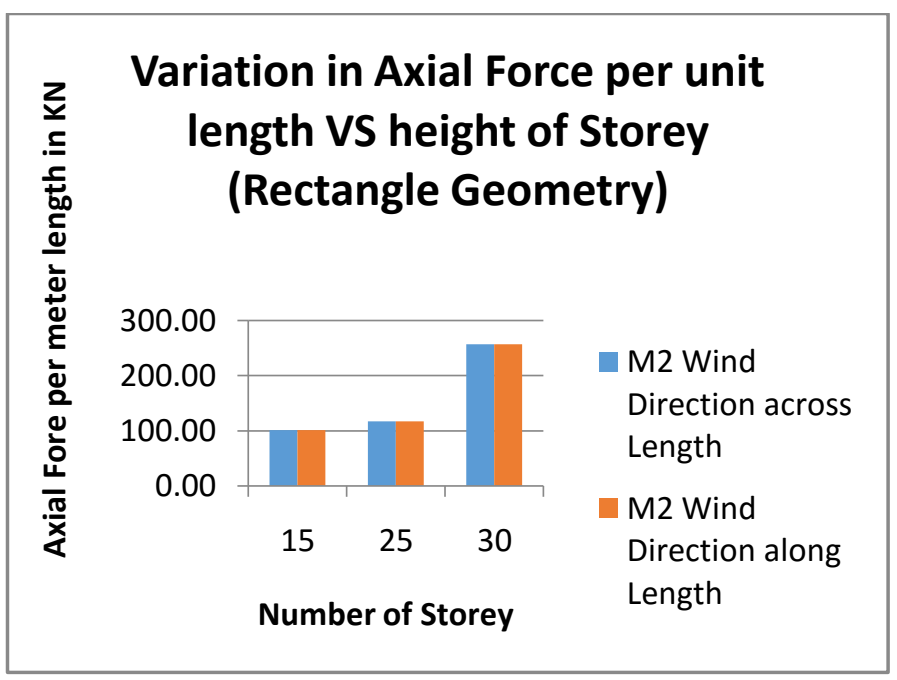

Chart -24: Variation in Axial Force per unit height in model M2 VS No. of storey 


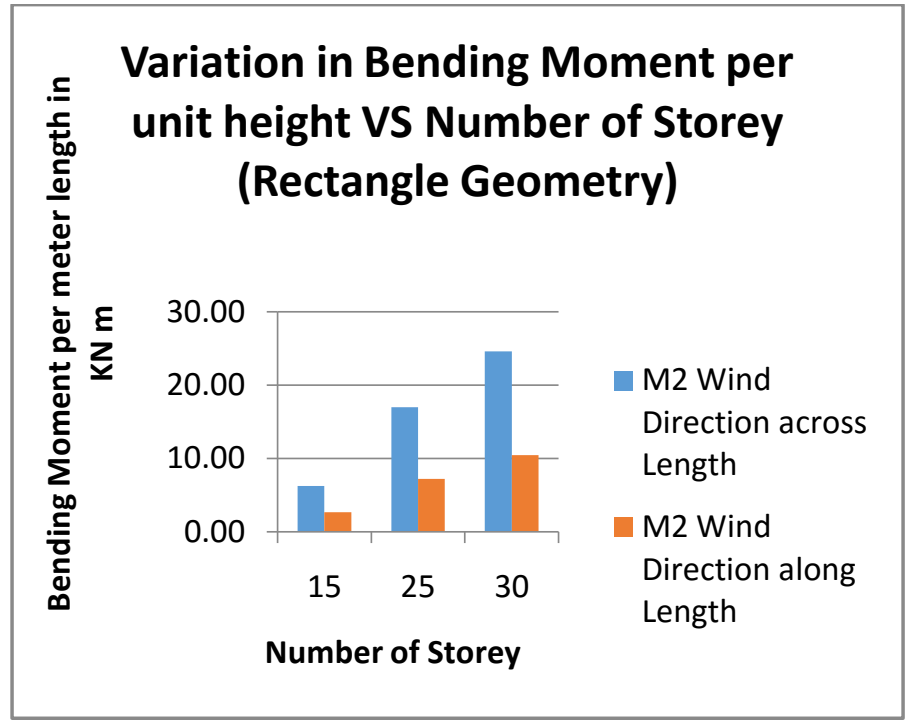

Chart -25: Variation in Bending Moment per unit height in model M2 VS No. of storey

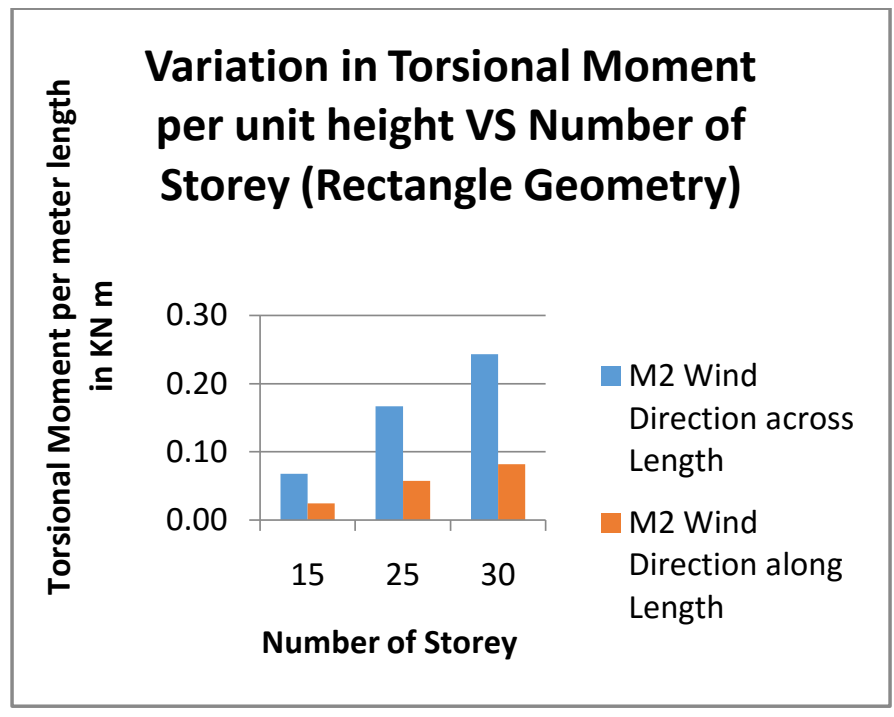

Chart -26: Variation in Bending Moment per unit height in model M2 VS No. of storey

From above charts (chart 19 to 26) it can be observed that maximum displacement, axial force, bending moment and torsional moment increases per unit length increases with increase in number of storey for both square and rectangular geometry whereas fluctuation is observer in case of shear force.

\section{CONCLUSION}

The following conclusions are drawn from the study:

1. The geometry of building plays an important role in controlling various parametric coefficients.

2. The square geometry is the most cost effective and serviceable among square and rectangular geometry.

3. If the placement of structure is such that wind direction is along the length of geometry, then the structure behaves better in case of rectangular geometry than that of square geometry.
4. Top displacement, storey drift, axial force, shear force, bending moment and torsional moment increases $48 \%$, $46 \%, 3 \%, 46 \%, 40 \%$ and $50 \%$ respectively in rectangle plan for critical load combination 1.5(DL+LL+WLX) with respect to square geometry when wind load is acting across the length.

5. Top displacement, storey drift, bending moment and torsional moment decreases $40 \%, 40 \%, 40 \%$, and $48 \%$ respectively in rectangle plan for critical load combination 1.5(DL+LL+WLZ) with respect to square geometry when wind load is acting along the length.

6. All the parametric coefficient increases per unit height.

\section{REFERENCES}

[1] J. A. Amin and A. K. Ahuja (2008), "Experimental study of wind pressures on irregular plan shape buildings". BBAA VI International Colloquium on: Bluff Bodies Aerodynamics \& Applications Milano, Italy.

[2] Yi Tang and Xin-yang Jin (2009), "Equivalent Static Wind Loads of an Asymmetric Building with 3D Coupled Modes". The Seventh Asia-Pacific Conference on Wind Engineering, Taipei, Taiwan.

[3] C.M. Chana, M.F. Huangb, K.C.S. Kwokc (2010), "Integrated wind load analysis and stiffness optimization of tall buildings with 3D modes". Engineering Structures 32 (2010) 12521261, Elsevier.

[4] Yi Hui n, Yukio Tamura, Akihito Yoshida (2012), "Mutual interference effects between two high-rise building models with different shapes on local peak pressure coefficients". J. Wind Eng. Ind. Aerodyn. 104-106 (2012) 98-108, Elsevier.

[5] Rachel Bashor,Sarah Bobby , Tracy Kijewski-Correa, Ahsan Kareem (2012) , "Full-scale performance evaluation of tall buildings under wind". J. Wind Eng. Ind. Aerodyn. 104-106 (2012) 88-97, Elsevier

[6] Michael Jesson, Mark Sterling, Chris Letchford, Chris Baker, (2015) "Aerodynamic forces on the roofs of low-, mid- and high-rise buildings subject to transient winds". J. WindEng.Ind.Aerodyn.143(2015)42-49, Elsevier.

[7] Mohamed Elsharawy, Khaled Galal, Ted Stathopoulos, (2015) "Torsional and shear wind loads on flat-roofed buildings". Engineering Structures 84 (2015) 313-324, Elsevier

[8] Indian standard codes, IS 875: part 2,3,5- 1987,“Code of practice for Design loads (other than earthquake) for buildings and structures."

[9] Indian standard code, IS 456: 2000, "Indian Standard code of practice for general structural use of plain and reinforced concrete." 